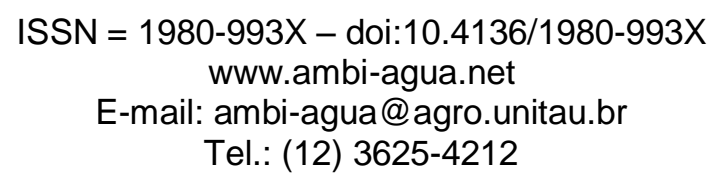

\title{
Caracterização geo-pedológica das áreas de nascentes na bacia hidrográfica do rio Piauitinga, Sergipe, Brasil
}

\author{
(http://dx.doi.org/10.4136/ambi-agua.767)
}

\author{
Leila Thais Soares Magalhães ${ }^{1}$; João Bosco Vasconcelos Gomes ${ }^{3}$; Anderson Nascimento \\ do Vasco'; Antenor de Oliveira Aguiar Netto ${ }^{1}$; Robério Anastácio Ferreira ${ }^{2}$ \\ ${ }^{1}$ Departamento de Engenharia Agronômica da Universidade Federal de Sergipe, São Cristovão, SE \\ ${ }^{2}$ Departamento de Engenharia Florestal da Universidade Federal de Sergipe, SE \\ ${ }^{3}$ Pesquisador da Empresa Brasileira de Pesquisa Agropecuária, Embrapa Florestas - Colombo - PR \\ e-mail: anderovasco@yahoo.com.br; antenor.ufs@gmail.com; \\ leilath24@gmail.com; raf@infonet.com.br; jbvgomes@cnpf.embrapa.br
}

\section{RESUMO}

Os estudos para recuperação e manutenção de áreas de nascentes têm papel fundamental na conservação dos recursos hídricos. Considerando a necessidade de recuperação das áreas do entorno das nascentes da bacia hidrográfica do rio Piauitinga (Lagarto, SE), foram caracterizados os solos de diferentes tipos de nascentes para servir como referencial entre áreas degradadas e em processo de recuperação. As nascentes foram classificadas quanto à sua recarga e quanto ao seu estado de conservação. Para o estudo dos solos locais, foram selecionadas as áreas de revegetação de cada nascente. Realizou-se a caracterização geopedológica dos sítios de estudo pela observação da paisagem local, pela abertura de microtrincheiras e por amostragem dos solos. Os solos foram descritos e classificados morfologicamente pelo Sistema Brasileiro de Classificação de Solos. Observou-se que de um total de 22 nascentes analisadas, apenas duas (9\%) foram consideradas como difusas, em relação à recarga e vinte $(91 \%)$ como pontuais. Em relação ao estado de conservação, cinco nascentes (22\%) foram identificadas como perturbadas e as demais como degradadas (88\%). Os sítios do entorno das nascentes do alto curso da bacia hidrográfica do rio Piauitinga foram distribuídos em posições erosicionais, baixadas e um único caso de sopé de encosta suave de tabuleiros costeiros. As características mais marcantes dos solos locais são o forte hidromorfismo (Gleissolos e Cambissolos gleissólicos) e, ou, o baixo grau de desenvolvimento (Cambissolos e Plintossolos, ambos com muito material esquelético, muitos com fase erodida).

Palavras-chave: Solos; Recuperação de áreas degradadas; Gestão ambiental.

\section{Soil classification of the Piauitinga river basin spring areas, Sergipe, Brazil}

\section{ABSTRACT}

The study of regeneration and maintenance of spring areas is fundamentally important for the conservation of water resources. Considering the need for restoration of the surrounding areas of the springs of the sub-basin of the Piauitinga River, in Lagarto-Sergipe, this study aimed to characterize the soils in their local environment which will serve as a benchmark for future comparisons between areas of springs already degraded and in the recovering process. The springs were classified according to their origin and their stage of 
preservation. For the study of the local soil, reforested areas of each spring were selected and grouped according to their position in the landscape. The soil classification of the study sites was performed based on local landscape observation, description of opened micro-trenches and analyses of soil samples. The soils were described and classified morphologically. It was observed that from 22 analyzed spring areas, only two (9\%) were considered according to their origin as diffuse and the remaining twenty (91\%) as punctual. Considering the preservation stage five spring areas (22\%) were identified as disturbed and the other ones as degraded (88\%). The sites around the springs' headwaters of the upper course of the Piauitinga river basin are located in erosion spots, depressions and a single case in the foothills coastal tablelands. The most striking characteristics of local soils are the strong hydromorphic (Gleissolos and gleic Cambisols) and, or, the low level of development (Cambisols and Plinthosols, both with much skeletal material, many of them in eroded phase).

Keywords: Soils; Recovery of degraded areas; Environmental management.

\section{INTRODUÇÃO}

O reconhecimento da importância da preservação ambiental não tem impedido que as necessidades humanas continuem sendo, muitas das vezes, satisfeitas em decorrência da exploração inadequada do meio ambiente. O processo de desmatamento é um dos expoentes dessa improfícua constatação, que acompanha sociedades atuais e passadas (Foley et al., 2005).

No caso das florestas fluviais, ações de desmatamento são extremamente impactantes, considerando que essas cumprem importantes serviços ambientais, principalmente o de proteger o solo e corpos de água e todos os reflexos disso na vida da população, inclusive da população urbana.

A bacia hidrográfica do rio Piauitinga, localizada na porção centro-sul do estado de Sergipe e responsável pelo abastecimento de água de alguns dos municípios do estado (Estância, Salgado, Lagarto e Boquim) não foge dessa realidade, com suas terras, inclusive aquelas enquadradas conforme Lei ${ }^{\circ} 4.771 / 65$ que instituiu o Código Florestal, quase em sua totalidade desmatadas (Moreira, 2008). Este desmatamento tem causado problemas ambientais que comprometem o volume e a qualidade das águas geradas pela unidade de planejamento em questão.

Nascentes são locais onde a água subterrânea aflora através da superfície do solo, formando um curso d'água (Pinto et al., 2004), ou seja, um ponto de recarga dos canais de drenagem das sub-bacias. Essas características tornam comum a presença de hidromorfismo nos solos que envolvem as nascentes. A presença de hidromorfismo à jusante das nascentes é uma constante nas bacias de inundação dos vales fluviais (Curcio, 2006) e de outras superfícies rebaixadas que constituem a ligação entre rios, córregos e lagoas (Martins et al., 2006). De forma pontual, se o canal de drenagem que começa em uma nascente for muito encaixado, o vale fluvial pode não ocorrer localmente, ou ser muito estreito. À montante das nascentes, posições de paisagem erosicionais convivem com solos de regime hídrico saturado e não-saturado, mas ganham importantes características de jovialidade (baixo grau de desenvolvimento) dos solos locais (Motta et al., 2002a).

Tendo em vista a necessidade de recuperação das áreas do entorno das nascentes da bacia hidrográfica do rio Piauitinga, em Lagarto, SE, o presente trabalho objetivou agrupar e caracterizar as paisagens e solos locais em diferentes nascentes, para servir como um referencial em futuras comparações, entre áreas de nascentes degradadas e em processo de recuperação ambiental. 
MAGAlHÃES, L. T. S.; GOMES, J. B. V.; VASCO, A. N.; AGUIAR NETTO, A. O.; FERREIRA, R. A. Caracterização geo-pedológica das áreas de nascentes na bacia hidrográfica do rio Piauitinga, Sergipe, Brasil. Ambi-Agua, Taubaté, v. 7, n. 1, p. 169-181, 2012. (http://dx.doi.org/10.4136/ambi-agua.767)

\section{MATERIAIS E MÉTODO}

A bacia hidrográfica do rio Piauitinga, afluente do rio Piauí, está situada no centro-sul do estado de Sergipe, compreendendo os municípios de Boquim, Estância, Lagarto, Salgado e Itaporanga D'Ájuda. Ela integra a meso-região geográfica do Agreste Sergipano (microrregião de Lagarto) e do Leste Sergipano (microrregiões de Boquim e Estância) e está localizada entre as coordenadas geográficas de $10^{\circ} 34^{\prime}$ e $10^{\circ} 45^{\prime} \mathrm{S}$ e $37^{\circ} 22^{\prime}$ e $37^{\circ} 34^{\prime} \mathrm{W}$. Compreende uma área de $411,98 \mathrm{~km}^{2}$ e seu perímetro é de $121,22 \mathrm{~km}$. A nascente do principal curso d'água desta bacia está localizada no povoado Brasília, pertencente ao município de Lagarto. Este curso recebe contribuição de 1.724 canais, com destaque para os riachos Grotão, Capivara, Riachão e Grilo. O rio Piauitinga possui 59,28 km de extensão e sua foz localiza-se próximo à sede do município de Estância, desembocando no rio Piauí (Moreira, 2008).

O clima da região do município de Lagarto é classificado como Megatérmico Subúmido, sendo que o valor médio anual da precipitação para o período de 1985 a 2005 foi de $1.182,8 \mathrm{~mm}$ (Sergipe, 2011). A temperatura média anual é de $28^{\circ} \mathrm{C}$, variando entre $22,3^{\circ} \mathrm{C}$, para os meses mais chuvosos e frios (julho a agosto), e $26^{\circ} \mathrm{C}$ para o período mais seco e quente (dezembro a março).

A região escolhida para o desenvolvimento da pesquisa concentrou-se no alto curso do rio Piauitinga entre as coordenadas $37^{\circ} 32^{\prime}$ e $37^{\circ} 36^{\prime} \mathrm{W}$ e $10^{\circ} 54^{\prime}$ e $10^{\circ} 57^{\prime} \mathrm{S}$, estando contida em sua totalidade no município de Lagarto. A área de estudo englobou 22 nascentes, que também estão inseridas no projeto "Adote um Manancial" (Figura 1), coordenado pelo Ministério Público, por meio da Promotoria de Meio Ambiente da Comarca de Lagarto, e pela Universidade Federal de Sergipe. Essas 22 nascentes encontram-se cercadas e nelas foi realizado o plantio de mudas nos meses de junho e julho de 2007 visando à recuperação ambiental. As espécies utilizadas na recomposição florestal foram: Angelim (Andira fraxinifolia Benth.), Angico (Anadenanthera colubrina (Vell.). Brenan), Aroeira (Schinus terebinthifolius Raddi.), Caju (Anacardium occidentali L.), Canafístula (Cassia grandis L. f.), Cedro (Cedrela fissilis Vell.), Ingá (Inga uruguensis Hook. et Arn.), Jatobá (Hymenaea courbaril L.), Jenipapo (Genipa americana L.), Maria-preta (Vitex polygama Cham.), Mauvizinho (Machaerium aculeatum Raddi), Mulungu (Erythrina velutina Willd.), Pau-brasil (Caesalpinia echinata Lam.), Pau-ferro (Caesalpinia leiostachya Benth.), Pau-pombo (Tapirira guianensis Aubl.), Saboneteria (Sapindus saponaria L.), Tamboril (Enterolobium contortisiliquum (Vell). Morong.).

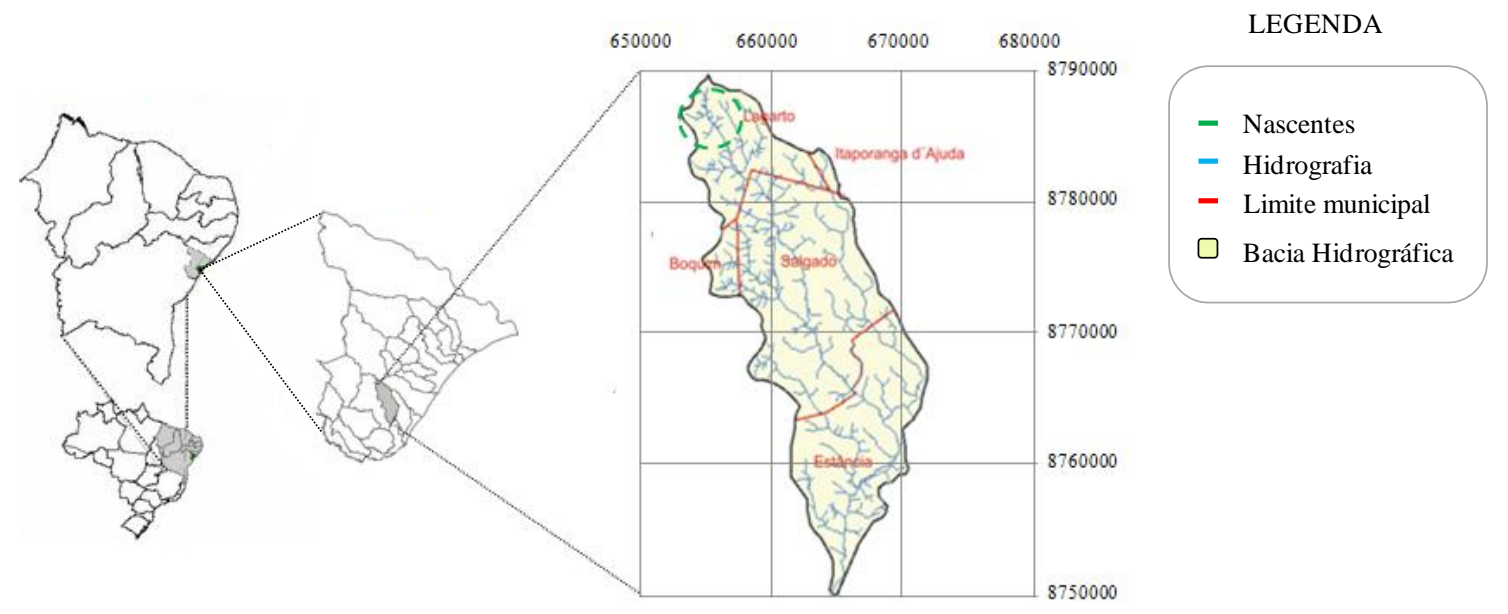

Figura 1. Nascentes do alto curso da bacia hidrográfica do rio Piauitinga, Lagarto-SE, englobadas pelo estudo. Fonte: Sergipe (2011). 
Parte das áreas de plantio abrangeram mais de uma nascente pela proximidade de seus vales de origem, podendo ocorrer a presença de nascentes em dupla ou tripleto dentro dessas áreas. Assim, tem-se 18 áreas de estudo, sendo três delas formadas por duas nascentes e uma por três nascentes.

As nascentes foram classificadas de acordo com Pinto et al. (2004) no que se refere a sua recarga como pontuais ou difusas, ou seja, pontuais aquelas que surgem na superfície em um único ponto e difusas as que surgem na superfície em vários pontos diferentes. As nascentes também foram classificadas em relação ao seu estado de conservação em conservadas (presença de pelo menos $50 \mathrm{~m}$ de vegetação natural em seu entorno, a partir do olho d'água), perturbadas (quando não apresenta $50 \mathrm{~m}$ de vegetação natural em seu entorno, mas apresenta bom estado de conservação) e degradadas (alto grau de perturbação, muito pouco vegetada, solo compactado, presença de gado, erosões e voçorocas).

Para o estudo dos solos locais foram selecionadas as áreas de revegetação de cada nascente (sítio). Se a nascente (de forma isolada, dupla ou tripleto) apresentou áreas de plantio de mudas à montante e à jusante da nascente em si, ela foi subdividida em parte alta e parte baixa (caso das nascentes 3-4, 10, 12 e 19-20-21).

A caracterização ambiental e pedológica dos sítios de estudo foi realizada pela observação da paisagem local, pela abertura de micro-trincheiras $(0,5 \times 0,5 \times 0,5 \mathrm{~m})$ e por tradagem dos solos de $0 \mathrm{~m}$ a $0,4 \mathrm{~m}$. Os solos foram descritos morfologicamente conforme (Santos et al., 2005) e classificados conforme EMBRAPA (2006), a partir das observações de campo. Para cinco pontos, amostras de solo foram coletadas e a fração argila separada por sedimentação após dispersão com $\mathrm{NaOH}\left(1 \mathrm{~mol} \mathrm{~L}^{-1}\right)$, confeccionando-se lâminas para a difração de raios-x, procurando definir a mineralogia dos solos locais nas encostas e nas áreas de baixada.

\section{RESULTADOS E DISCUSSÃO}

Os valores obtidos para a classificação das nascentes, bem como as atividades desenvolvidas nas suas áreas e/ou proximidades podem ser vistas na Tabela 1. Verificou-se que de um total de 22 nascentes analisadas, apenas duas $(9 \%)$ são consideradas em relação à recarga como difusas e vinte $(91 \%)$ como pontuais. Em relação ao estado de conservação foram identificadas cinco nascentes $(22 \%)$ como perturbadas e as demais como degradadas $(88 \%)$. Isto significa que no alto curso da bacia hidrográfica do rio Piauitinga não há registro de nascentes conservadas.

Uma situação um pouco mais branda, porém, não menos preocupante, foi observada em numa bacia hidrográfica próxima da região. Observou-se que as 20 principais nascentes dos rios e tributários que compõem a sub-bacia hidrográfica do rio Poxim, apresentam alterações decorrentes da acelerada antropização (90\%), a maioria delas (65\%) com elevada degradação (sem raio mínimo de $50 \mathrm{~m}$ de vegetação) e ocupadas por agricultura $(50 \%)$ e pastagens $(35 \%)$. Somente duas nascentes encontram-se preservadas (Ferreira et al., 2011). A conservação da vegetação nas áreas de nascentes assegura a conservação de sua perenidade e a qualidade de suas águas por propiciar maior infiltração das águas das chuvas no solo e, consequentemente, a recarga do lençol freático e alimentação das nascentes, ajudando a conservação dos recursos hídricos. Pinto et al. (2004) ao realizarem análise das vazões das nascentes observaram que as classificadas como preservadas apresentaram, em média, os maiores valores de vazão, destacando-se as nascentes pontuais. 
MAGAlhães, L. T. S.; GOMES, J. B. V.; VASCO, A. N.; AGUIAR NETTO, A. O.; FERREIRA, R. A. Caracterização geo-pedológica das áreas de nascentes na bacia hidrográfica do rio Piauitinga, Sergipe, Brasil. Ambi-Agua, Taubaté, v. 7, n. 1, p. 169-181, 2012. (http://dx.doi.org/10.4136/ambi-agua.767)

Tabela 1. Classificação das nascentes do alto curso do rio Piauitinga, Lagarto-SE, quanto ao tipo de recarga, ao estado de conservação e uso e/ou ocupação do solo das respectivas áreas e ou proximidades.

\begin{tabular}{clll}
\hline Nascentes & Recarga & $\begin{array}{c}\text { Estado de } \\
\text { conservação }\end{array}$ & \multicolumn{1}{c}{ Uso e/ou ocupação do solo } \\
\hline 1 & Pontual & Degradada & Cultivo de cana-de-açúcar \\
2 & Pontual & Degradada & Cultivo de cana-de-açúcar \\
3 & Pontual & Degradada & Extração de areia e pastagem \\
4 & Pontual & Degradada & Extração de areia e pastagem \\
5 & Difusa & Perturbada & Pastagem \\
6 & Pontual & Degradada & Área em regeneração natural \\
7 & Pontual & Degradada & Pastagem \\
8 & Difusa & Degradada & Pastagem \\
9 & Pontual & Degradada & Área em regeneração natural \\
10 & Pontual & Degradada & Cultivo de coco e pastagem \\
11 & Pontual & Degradada & Cultivo de coco, macaxeira, banana, maracujá e pastagem \\
12 & Pontual & Degradada & Pastagem \\
13 & Pontual & Degradada & Agricultura, pastagem e ocupação urbana \\
14 & Pontual & Degradada & Agricultura, pastagem e ocupacão urbana \\
15 & Pontual & Degradada & Pastagem e ocupação urbana \\
16 & Pontual & Degradada & Pastagem \\
17 & Pontual & Degradada & Cultivo de cana-de-açúcar e pastagem \\
18 & Pontual & Degradada & Área em regeneração natural \\
19 & Pontual & Perturbada & Área em regeneração natural \\
20 & Pontual & Perturbada & Área em regeneração natural \\
21 & Pontual & Perturbada & Área em regeneração natural \\
22 & Pontual & Perturbada & Cultivo de coco, laranja, limão, tangerina e banana \\
\hline
\end{tabular}

As áreas de estudo foram reagrupadas a partir de suas posições na paisagem e das características dos solos locais em cinco grupos: baixada (BA), encosta com horizonte A (na superfície do solo) (EA), encosta sem horizonte A (ES), encosta com hidromorfismo (EH) e sopé de encosta (SE), conforme as Tabelas 2 e 3.

O sítio (SE) destaca-se tanto por sua posição na paisagem, sopé de encosta suave de uma elevação de topo amplo de tabuleiros costeiros cultivada com citrus (Figura 2A), como do ponto de vista da drenagem associada à nascente local. A drenagem aparece encaixada (depósito de canal), caracterizando uma ruptura abrupta entre a área de estudo (sopé da encosta) e o leito do riacho originado na nascente, que é do tipo vertical, indicativa da juventude do riacho, não ocorrendo localmente um vale fluvial. As outras nascentes ocorrem após quebras de relevo de elevações de tabuleiros costeiros. As encostas dessas quebras de relevo ocorrem em relevo ondulado a forte ondulado, podendo ocorrer níveis intermediários planos a quase planos (Figuras 2B e 2C). Os sítios dos grupos EA, ES e EH localizam-se nessas escarpas erosivas, à montante das nascentes. Os sítios BA estão em vales fluviais abertos, que ocorrem à jusante das nascentes estudadas. São depósitos nas bacias de decantação dos vales fluviais locais, com elevado grau de hidromorfia. Assim, à exceção da nascente do sítio SE, as demais são cabeceiras de drenagem de vales formados por processos de erosão areolar (lateral) e com drenagens de maior senelidade, dominantes na região de estudo. 
MAGAlhãeS, L. T. S.; GOMES, J. B. V.; VASCO, A. N.; AGUIAR NETTO, A. O.; FERREIRA, R. A. Caracterização geo-pedológica das áreas de nascentes na bacia hidrográfica do rio Piauitinga, Sergipe, Brasil. Ambi-Agua, Taubaté, v. 7, n. 1, p. 169-181, 2012. (http://dx.doi.org/10.4136/ambi-agua.767)

Tabela 2. Agrupamento dos pontos de amostragem das áreas do entorno das nascentes de acordo com suas posições na paisagem e características morfológicas dos solos das nascentes do alto curso do rio Piauitinga, Lagarto, SE.

\begin{tabular}{l|c|c}
\hline \multicolumn{1}{c|}{ Grupo } & Sítios & Nascentes \\
\hline \multirow{3}{*}{ Baixada (BA) } & BA1 & 3 e 4 (parte baixa) \\
& BA2 & 5 e 6 \\
& BA3 & 10 (parte baixa) \\
& BA4 & 11 \\
& BA5 & 12 (parte baixa) \\
Encosta com Horizonte A & BA6 & 19,20 e 21 (parte baixa) \\
(EA) & EA1 2 \\
& EA2 & 10 (parte alta) \\
& EA3 & 15 e 16 \\
Encosta com & EH1 & 7 \\
Hidromorfismo (EH) & EH2 & 8 e 9 \\
& EH3 & 17 \\
\hline & EH4 & 3 e 4 (parte alta) \\
Encosta sem Horizonte A & ES1 & 12 (parte alta) \\
(ES) & ES2 & 13 e 14 \\
& ES3 & 19,20 e 21 (parte alta) \\
\hline Sopé de Encosta (SE) & ES4 & SE \\
\hline
\end{tabular}

Tabela 3. Características ambientais das áreas agrupadas de acordo com suas posições geormorfológicas, dos solos das nascentes do alto curso do rio Piauitinga, Lagarto, SE.

\begin{tabular}{c|c|l}
\hline Áreas & Código & \multicolumn{1}{c}{ Características } \\
\hline Baixada & BA & Vale com forte presença de hidromorfismo. \\
\hline $\begin{array}{c}\text { Encosta com presença de } \\
\text { horizonte A }\end{array}$ & EA & $\begin{array}{l}\text { Encosta em quebra de relevo de tabuleiros, com } \\
\text { presença de vegetação suficiente para sustentar } \\
\text { horizonte superficial escurecido por C orgânico. }\end{array}$ \\
\hline $\begin{array}{c}\text { Encosta sem presença de } \\
\text { horizonte A }\end{array}$ & ES & $\begin{array}{l}\text { Encostas em quebra de relevo de tabuleiros, em áreas } \\
\text { com ausência de cobertura vegetal e solos destituídos } \\
\text { de horizonte A (cores denotam baixos teores de C } \\
\text { orgânico). Solos naturalmente erodidos (grotas) ou } \\
\text { decapitados por atividade antrópica (retirada de } \\
\text { material de empréstimo). }\end{array}$ \\
\hline $\begin{array}{c}\text { Encosta com presença de } \\
\text { hidromorfismo }\end{array}$ & EH & $\begin{array}{l}\text { Encostas em quebra de relevo de tabuleiros com } \\
\text { presença de hidromorfismo nos solos locais. Os solos } \\
\text { variam quanto a presença ou ausência de horizonte A } \\
\text { e de cobertura vegetal. }\end{array}$ \\
\hline $\begin{array}{c}\text { Sopé de encosta } \\
\text { final de encosta suave em tabuleiro extenso, com } \\
\text { nascente pontual surgindo de forma abrupta (pequeno } \\
\text { vale encaixado). }\end{array}$ \\
\hline
\end{tabular}



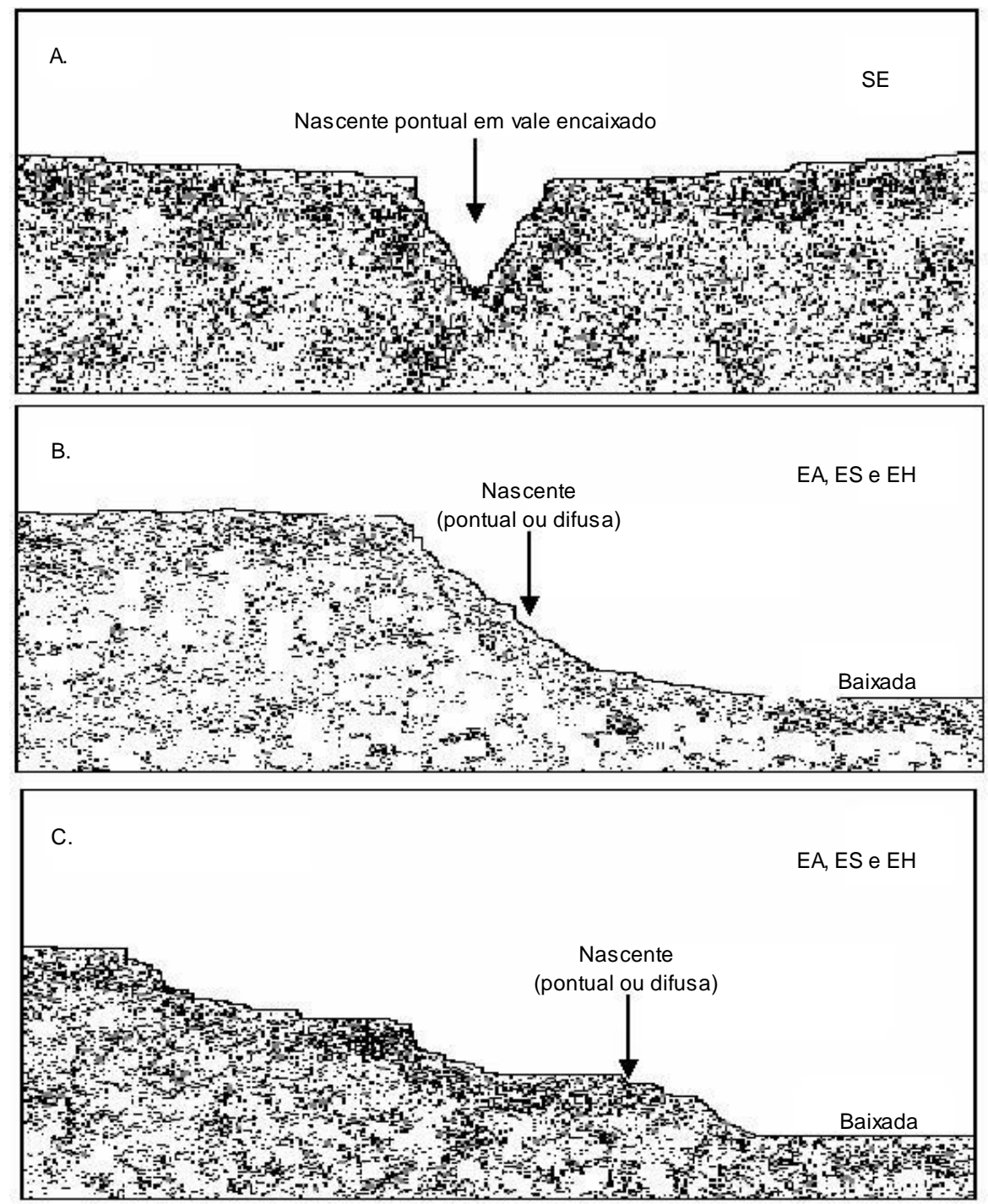

Figura 2. Esquemas mostrando as diferentes posições de amostragem na bacia hidrográfica do rio Piauitinga, Lagarto-SE, conforme a superfície geomorfológica. (A) Vale encaixado, que se origina em encosta suave de um topo amplo de elevação. (B) Vale aberto (com baixada), que se origina a partir de encosta que alcança o topo de elevação. (C) Vale aberto (com baixada), que se origina a partir de encosta que alcança nível intermediário entre o topo da paisagem e a baixada.

Como uma característica geral dos solos estudados, difrações de raios-X da fração argila mostraram uma mineralogia amplamente dominada por caulinita na fração argila, aparecendo ainda algum quartzo (Figura 3). Essa mineralogia é típica de materiais do Barreiras (Ferreira et al., 1999; Duarte et al., 2000) e se repetiu mesmo nas amostras das encostas após quebras de relevo (ES1, EH2 e EA2) e na baixada (BA6), descartando a presença de argilo-minerais do tipo 2:1 que representassem algum diferencial na reserva de nutrientes dos solos locais. $\mathrm{O}$ grupo Barreiras é constituído por sedimentos terrígenos (cascalho, conglomerados, areia finas e grossa e níveis de argila), sendo esses pouco consolidados e estratificados irregularmente, com a fração grosseira do sedimento basicamente constituída de quartzo (Duarte et al., 2000). No caso dos sítios BA, formados por sedimentos holocênicos, estes repetiram a composição mineralógica dos materiais à montante. 


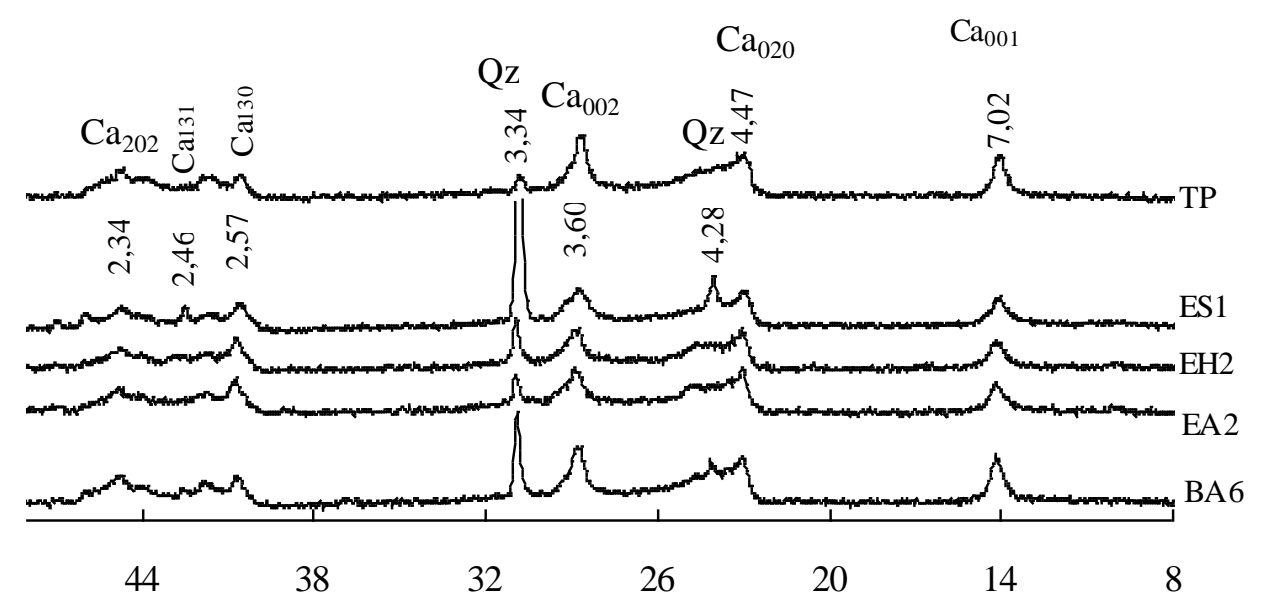

Graus $2 \theta$

Figura 3. Difratogramas de raios-X de amostras em pó da fração argila de solos do entorno de nascentes do alto rio Piauitinga, Lagarto-SE. Amostras de 0,1 a $0,3 \mathrm{~m}$ de profundidade. TP - sopé de encosta, ES1 - encosta sem horizonte A, $\mathrm{EH} 2$ - encosta com hidromorfismo, EA2 - encosta com horizonte A e BA6 Baixada.

Duas características são marcantes nos solos dos sítios BA. O excesso de água (hidromorfismo), expressado morfologicamente pelas cores do solo neutras, ou de cromas baixos (Guertal e Hall, 1990), e o relevo plano a quase plano. A proximidade das cabeceiras de drenagem não permitiu o aparecimento de depósitos de margem, com Neossolos Flúvicos relativamente mais bem drenados.

As alturas relativas dos depósitos locais em relação ao nível freático determinaram poucas diferenças no grau de desenvolvimento pedogenético e nos níveis de hidromorfia. Apenas BA5 não foi classificado como Gleissolo (Tabela 4), sendo classificado como um Cambissolo Háplico Tb Distrófico gleissólico. Nele, o lençol freático apresenta-se um pouco mais rebaixado, embora a vegetação atual mantenha-se como campo úmido.

Nesse sentido, é necessária uma melhor caracterização dos regimes hídricos locais, atentando para que solos com saturação hídrica plena por longos períodos dificultam, ou mesmo impedem (Curcio, 2006) as coberturas arbóreas. A presença ou ausência de árvores em ambientes com hidromorfia ainda pode conter variáveis locais que fazem a diferença. Motta et al. (2002b) postularam que a vegetação de campo pode ser favorecida por uma sazonalidade hídrica local, que por sua vez desfavoreceria o aparecimento de indivíduos lenhosos. Nessa hipótese, a presença de florestas em áreas mal a muito mal drenadas seria muito sensível a sucessão de períodos com deficiência e excesso de água no solo, mais do que a presença do hidromorfismo em si.

Os autores consideraram a existência de indivíduos lenhosos adaptados ao excesso de água, caso das espécies com estruturas especializadas em trocas gasosas, mas que não suportam conviver com estresses antagônicos e que exigem de sua parte estratégias de sobrevivência também antagônicas (Motta et al., 2002b). Considerando-se as características discutidas, é difícil prever as taxas de sobrevivência das espécies arbóreas em revegetação nos solos das baixadas locais, mas deve-se considerar que a predominância de hidromorfia a semihidromorfia restringe amplamente a entrada de espécies mesófilas, possibilitando maior espaço para plantas arbóreas hidrófilas e higrófilas (Curcio, 2006).

Os sítios dos grupos EA, ES e EH estão em posições de paisagem erosicionais (escarpas erosivas). Essas posições, quando relacionadas às coberturas sedimentares, no caso 
MAGAlhães, L. T. S.; GOMES, J. B. V.; VASCO, A. N.; AGUIAR NETTO, A. O.; FERREIRA, R. A. Caracterização geo-pedológica das áreas de nascentes na bacia hidrográfica do rio Piauitinga, Sergipe, Brasil. Ambi-Agua, Taubaté, v. 7, n. 1, p. 169-181, 2012. (http://dx.doi.org/10.4136/ambi-agua.767)

sedimentos do grupo Barreiras, apresentam exposição muito frequente de corpos de petroplintita, como os aqui observados (Tabela 4). Esses corpos ajudam a frear o processo erosivo a montante (Motta et al., 2002a), desacelerando a dissecação da paisagem. Também é comum a ocorrência de pavimento pedregoso na superfície dos solos locais. Independente da presença de vegetação, esses pavimentos são importantes na desaceleração de processos erosivos de maior amplitude (Poesen e Ingelmo-Sanchez, 1992).

A diferença entre os solos (Cambissolos e Plintossolos) dos sítios EA e ES ocorre pela presença ou ausência de horizonte A, como observado no campo. Nos sítios EA, a presença local de cobertura vegetal foi suficiente para incorporar ao solo biomassa e atividade biológica em sua superfície, formando um horizonte A de fraco a moderado (EMBRAPA, 2006). Em ES, todos os solos são fase erodida. A ausência de horizonte A nos solos de ES pode ser por características das paisagens locais, que por vezes formam pavimentos desérticos (ES2, ES3 e ES4), ou pela ação antrópica, como em ES1. A presença de material esquelético nos solos dos dois grupos é uma constante, como já comentado. Esse material é composto, basicamente, de corpos de quartzo e petroplintita.

Tabela 4. Características do solo em sua ambiência nos pontos de amostragem das nascentes do alto curso da bacia hidrográfica do rio Piauitinga, Lagarto-SE.

\begin{tabular}{|c|c|c|c|c|c|c|c|}
\hline Sítios & $\begin{array}{l}\text { Classe de } \\
\text { solo }^{(1)}\end{array}$ & Textura $^{(2)}$ & $\begin{array}{l}\text { Cor superficial e } \\
\text { subsuperficial }\end{array}$ & $\begin{array}{l}\text { Mosquea } \\
\text { do (e, ou, } \\
\text { plintita) }\end{array}$ & $\begin{array}{c}\text { Presença de } \\
\text { impedimento } \\
\text { (lençol freático e } \\
\text { material } \\
\text { esquelético) } \\
\end{array}$ & Relevo & $\begin{array}{l}\text { Cobertura } \\
\text { atual }\end{array}$ \\
\hline \multicolumn{8}{|c|}{ BAIXADA } \\
\hline BA1 & GX & FRA/RA & $10 \mathrm{YR} 3 / 2$ e $4 / \mathrm{N}$ & - & $\begin{array}{l}\text { faixa cascalhenta aos } \\
0,15 \mathrm{~m} \text { e lençol aos } \\
0,6 \mathrm{~cm} \text {. }\end{array}$ & $\begin{array}{l}\text { plano a } \\
\text { quase plano }\end{array}$ & campo úmido \\
\hline BA2 & GM & $\mathrm{R} / \mathrm{RR}$ & $3,5 / \mathrm{N}$ e $5 / \mathrm{N}$ & 7,5YR 5/5 & $\begin{array}{l}\text { lençol freático a } \\
0,5 \mathrm{~m} .\end{array}$ & $\begin{array}{l}\text { plano a } \\
\text { quase plano }\end{array}$ & campo úmido \\
\hline BA3 & GX & $\mathrm{R} / \mathrm{RR}$ & $2,5 / \mathrm{N}$ e $5 / \mathrm{N}$ & - & $\begin{array}{l}\text { lençol freático a } \\
0,65 \mathrm{~m}\end{array}$ & $\begin{array}{l}\text { plano a } \\
\text { suave } \\
\text { ondulado }\end{array}$ & campo úmido \\
\hline BA4 & GX & FRA/RA & & - & $\begin{array}{l}\text { lençol freático a } \\
0,7 \mathrm{~m} \text {. }\end{array}$ & $\begin{array}{l}\text { plano a } \\
\text { quase plano }\end{array}$ & campo úmido \\
\hline BA5 & CXg & $\mathrm{FS} / \mathrm{F} / \mathrm{FR}$ & $\begin{array}{l}\text { 10YR 4/3, 10YR } 5 / 2 \mathrm{e} \\
10 \mathrm{YR} 5 / 4\end{array}$ & 7,5YR 5/6 & $\begin{array}{l}\text { até } 1,5 \mathrm{~m} \text { de } \\
\text { profundidade } \\
\text { (tradagem) }\end{array}$ & $\begin{array}{l}\text { plano a } \\
\text { quase plano }\end{array}$ & campo úmido \\
\hline BA6 & GX & FA/FRA/RA & $10 \mathrm{YR} 4 / 2$ e $10 \mathrm{YR} 5 / 2$ & 7,5 YR 5/6 & $\begin{array}{l}\text { lençol freático a } \\
0,75 \mathrm{~m} \text {. }\end{array}$ & $\begin{array}{l}\text { plano a } \\
\text { quase plano }\end{array}$ & campo úmido \\
\hline \multicolumn{8}{|c|}{ ENCOSTA COM PRESENÇA DE HORIZONTE A } \\
\hline EA1 & FX & $\mathrm{RA} / \mathrm{R} / \mathrm{RR}$ & $\begin{array}{l}\text { 7,5YR 4/2, 7,5YR5/4 e } \\
\text { 7,5YR 5/5 } \\
\text { 7,5YR 4/4, 7,5YR 5/5, } \\
\text { 7,5YR 5/6 e 10YR 5/5 }\end{array}$ & \begin{tabular}{l}
\multicolumn{1}{c}{-} \\
(plintita \\
$2,5 \mathrm{YR} 4 / 5$ ) \\
$2,5 / \mathrm{Ne}$ \\
$2,5 \mathrm{YR} \mathrm{5/5}$ \\
(plintita \\
2,5YR 4/6)
\end{tabular} & $\begin{array}{l}\text { faixa cascalhenta de } \\
0 \text { a } 0,1 \mathrm{~m} . \\
\text { pavimento } \\
\text { pedregoso }\end{array}$ & $\begin{array}{l}\text { plano a } \\
\text { suave } \\
\text { ondulado } \\
\text { ondulado }\end{array}$ & $\begin{array}{l}\text { pousio com } \\
\text { capoeira } \\
\text { aberta } \\
\text { pastagem } \\
\text { nativa e } \\
\text { degradada }\end{array}$ \\
\hline EA3 & $\begin{array}{l}\text { CX } \\
\text { petroplín } \\
\text { tico }\end{array}$ & $\mathrm{RA} / \mathrm{R} / \mathrm{RR}$ & $\begin{array}{l}10 \text { YR } 4 / 5,7,5 \text { YR } 4 / 2 \\
7,5 \text { YR } 5 / 6 \text { e } 6 \text { YR } 5 / 6\end{array}$ & $\begin{array}{l}\text { petroplintit } \\
\text { a } 10 \mathrm{R} 5 / 5\end{array}$ & $\begin{array}{l}\text { pavimento } \\
\text { pedregoso } \\
\text { (dominância de } \\
\text { calhaus, com alguns } \\
\text { matacões de } \\
\text { petroplintita) e corpo } \\
\text { do solo com } \\
\text { cascalho }\end{array}$ & $\begin{array}{l}\text { forte } \\
\text { ondulado }\end{array}$ & $\begin{array}{l}\text { pastagem } \\
\text { nativa e } \\
\text { degradada }\end{array}$ \\
\hline
\end{tabular}


MAGAlhães, L. T. S.; GOMES, J. B. V.; VASCO, A. N.; AGUIAR NETTO, A. O.; FERREIRA, R. A.

Caracterização geo-pedológica das áreas de nascentes na bacia hidrográfica do rio Piauitinga, Sergipe, Brasil.

Ambi-Agua, Taubaté, v. 7, n. 1, p. 169-181, 2012. (http://dx.doi.org/10.4136/ambi-agua.767)

\section{ENCOSTA COM PRESENÇA DE HIDROMORFISMO}

\begin{tabular}{|c|c|c|c|c|c|c|c|}
\hline EH1 & GX & FRA/FA/RA & $10 \mathrm{YR} 4 / 1,4 / \mathrm{N}$ e $6 / \mathrm{N}$ & 10YR6/7 & $\begin{array}{l}\text { pavimento } \\
\text { pedregoso } \\
\text { (calhaus), linha de } \\
\text { pedra a } 0,18 \mathrm{~m} \\
\text { (entre horizontes } \\
\text { A e AC) e lençol } \\
\text { freático a } 1 \mathrm{~m} \text { de } \\
\text { profundidade }\end{array}$ & $\begin{array}{l}\text { forte } \\
\text { ondulado } \\
\text { a suave } \\
\text { ondulado }\end{array}$ & $\begin{array}{l}\text { campo } \\
\text { úmido }\end{array}$ \\
\hline EH2 & $\mathrm{CXg}$ & RA/RR/R & $\begin{array}{l}\text { 10YR 4/2,5, 10YR 4/3, } \\
10 \mathrm{YR} 6 / 1 \text { e } 8 / \mathrm{N}\end{array}$ & $\begin{array}{l}2,5 \text { YR } 4 / 8 \\
7,5 \text { YR } 5 / 6\end{array}$ & $\begin{array}{l}\text { superfície com } \\
\text { algum calhau }\end{array}$ & ondulado & $\begin{array}{l}\text { pousio com } \\
\text { poacea e } \\
\text { partes sem } \\
\text { vegetação }\end{array}$ \\
\hline EH3 & $\mathrm{CXg}$ & $\mathrm{RA} / \mathrm{R}$ & $10 \mathrm{YR} 4 / 3,5$ e $6 / \mathrm{N}$ & \begin{tabular}{l}
\multicolumn{1}{c}{-} \\
(plintita \\
2,5YR 4/5)
\end{tabular} & $\begin{array}{l}\text { pavimento } \\
\text { pedregoso com } \\
\text { matacões de } \\
\text { petroplintita }\end{array}$ & $\begin{array}{l}\text { forte } \\
\text { ondulado }\end{array}$ & $\begin{array}{l}\text { capoeira } \\
\text { aberta }\end{array}$ \\
\hline EH4 & GX & FRA & $3 / \mathrm{N}$ e $7 / \mathrm{N}$ & - & $\begin{array}{l}\text { cascalhento (aos } \\
0,55 \mathrm{~m} \text { ) e lençol } \\
\text { freático a } 1,10 \mathrm{~m}\end{array}$ & ondulado & $\begin{array}{l}\text { pousio com } \\
\text { capoeira } \\
\text { aberta }\end{array}$ \\
\hline Sítios & $\begin{array}{c}\text { Classe } \\
\text { de solo }\end{array}$ & Textura $^{(2)}$ & $\begin{array}{l}\text { Cor superficial e } \\
\text { subsuperficial }\end{array}$ & $\begin{array}{l}\text { Mosqueado } \\
\text { (e, ou, } \\
\text { plintita) }\end{array}$ & $\begin{array}{l}\text { Presença de } \\
\text { impedimento (lençol } \\
\text { freático e material } \\
\text { esquelético) }\end{array}$ & Relevo & $\begin{array}{l}\text { Cobertura } \\
\text { atual }\end{array}$ \\
\hline
\end{tabular}

ENCOSTA SEM PRESENÇA DE HORIZONTE A

\begin{tabular}{|c|c|c|c|c|c|c|c|}
\hline ES1 & $\begin{array}{l}\text { C fase } \\
\text { erodida } \\
\text { (solo } \\
\text { raspado) }\end{array}$ & FRA/FR & 2,5YR 4/6 e $10 \mathrm{YR} 6 / 8$ & - & $\begin{array}{l}\text { superfície e corpo do } \\
\text { solo com calhau, que } \\
\text { é cascalhento a } \\
\text { muito cascalhento }\end{array}$ & $\begin{array}{l}\text { plano } \\
\text { (paisagem } \\
\text { alterada } \\
\text { pela } \\
\text { extração de } \\
\text { material) } \\
\end{array}$ & ausente \\
\hline ES2 & $\begin{array}{l}\text { F fase } \\
\text { erodida } \\
\text { (solo } \\
\text { raspado) }\end{array}$ & $\begin{array}{l}\text { (grande } \\
\text { predominância } \\
\text { de material } \\
\text { esquelético) }\end{array}$ & $5 Y R 5 / 6$ & $\begin{array}{l}\text { - } \\
\text { (plintita } \\
\text { 10R } 3 / 6 \text { e } \\
\text { 7N entre } 10 \\
\text { e } 30 \mathrm{~cm} \text { ) }\end{array}$ & $\begin{array}{l}\text { superfície com muito } \\
\text { calhau, cascalho de } \\
\text { quartzo e } \\
\text { petroplintita e alguns } \\
\text { matacões, sulcos de } \\
\text { erosão }\end{array}$ & $\begin{array}{l}\text { forte } \\
\text { ondulado a } \\
\text { suave } \\
\text { ondulado }\end{array}$ & ausente \\
\hline ES3 & $\begin{array}{l}\mathrm{F} \text { fase } \\
\text { erodida }\end{array}$ & $\mathrm{RA} / \mathrm{R} / \mathrm{RR}$ & 8,5 YR $5 / 5$ e $10 Y R 7 / 6$ & $\begin{array}{l}5 Y R 5 / 8 \\
\text { (plintita e } \\
\text { petroplintit } \\
\text { a 10R 3/5) }\end{array}$ & $\begin{array}{l}\text { pavimento } \\
\text { pedregoso com } \\
\text { presença de } \\
\text { matacões de } \\
\text { petroplintita }\end{array}$ & $\begin{array}{l}\text { forte } \\
\text { ondulado }\end{array}$ & $\begin{array}{l}\text { pousio com } \\
\text { vegetação } \\
\text { muito rala }\end{array}$ \\
\hline ES4 & $\begin{array}{l}\text { F fase } \\
\text { erodida } \\
\text { (solo } \\
\text { raspado) }\end{array}$ & $\begin{array}{l}\mathrm{FRA} / \mathrm{F} \text { e } \\
\mathrm{FR} / \mathrm{RS} / \mathrm{R}\end{array}$ & $\begin{array}{l}10 \mathrm{YR} 4 / 4,5 \mathrm{YR} 4 / 3 \mathrm{e} \\
8 / \mathrm{N}\end{array}$ & $\begin{array}{l}8 / \mathrm{N} \text { e } \\
10 \mathrm{R} 4 / 6\end{array}$ & $\begin{array}{l}\text { superfície com } \\
\text { calhaus e matacões } \\
\text { de petroplintita }\end{array}$ & $\begin{array}{l}\text { plano a } \\
\text { quase } \\
\text { plano }\end{array}$ & ausente \\
\hline
\end{tabular}

\section{SOPÉ DE ENCOSTA}

\begin{tabular}{c|l|l|l|l|l|l|l}
\hline SE & PAC & A/AF/FA/FRA & $\begin{array}{l}\text { 10YR 4/2, 10YR4/2,5 } \\
\text { e 10YR 5/1 }\end{array}$ & $\begin{array}{l}\text { 10YR 5/2 } \\
\text { e 10YR } \\
6 / 8\end{array}$ & $\begin{array}{l}\text { ausência de lençol } \\
\text { freático até 1,35 m }\end{array}$ & $\begin{array}{l}\text { plano de } \\
\text { sopé de } \\
\text { encosta } \\
\text { poacea } \\
\text { (capetinga } \\
\text { e carrapicho) }\end{array}$ \\
\hline
\end{tabular}

${ }^{(1)}$ GX: Gleissolo Háplico; GM: Gleissolo Melânico; CXg: Cambissolo Háplico gleissólico; FX: Plintosolo Háplico; CXpetroplíntico: Cambissolo Háplico petroplíntico; C fase erodida: Cambissolo fase erodida; F fase erodida: Plintossolo fase erodida; PAC: Argissolo Acinzentado.

${ }^{(2)}$ A: arenosa; AF: areia-franca; FA: franco-arenosa; F: franca; FR: franco-argilosa; FRA: franco-argilo-arenosa;

RA: argila-arenosa; R: argila; RR: muito argilosa; FS: franco-siltosa; RS: argilo-siltosa. 
Os solos EH também representam posições de encosta, mas localizam-se no entorno de áreas de surgência, onde o hidromorfismo é uma constante. Como nos solos de baixada, cores neutras aparecem, mesmo em relevo predominantemente ondulado a forte ondulado. A vegetação atual volta a ser campo úmido. A presença de mosqueado é mais frequente que nos solos BA, pois aqui a flutuação entre o excesso e a ausência de água no perfil apresenta maior número de ciclos ao longo do ano, permitindo que zonas de oxidação apresentem mosqueados com maior frequência (Motta et al., 2002a).

A posição abaciada do sítio SE (relevo plano no entorno de nascente vertical) originou Argissolos Acinzentados, caracterizados por cores de valores relativamente altos e cromas baixos se comparados a outros Argissolos (EMBRAPA, 2006). Ocorre algum excesso de água sazonal, mas não deve ser suficiente para que ocorram problemas com o desenvolvimento das mudas locais. A posição dos solos em final de encosta melhora o regime de umidade desses solos, diminuindo a deficiência de água ao longo do ano relativamente aos solos à montante (Argissolos Amarelos), bem como diminuindo a expressão da coesão, comum aos solos dos tabuleiros costeiros (Gomes et al., 2008; Lima Neto et al., 2009) e que poderia dificultar o desenvolvimento de mudas plantadas na restauração da área.

\section{CONCLUSÃO}

Os sítios do entorno das nascentes do alto curso da bacia hidrográfica do rio Piauitinga estão distribuídos em posições erosicionais (quebra-de-relevo), baixadas e um único caso de sopé de encosta suave de topo de tabuleiros costeiros.

Para os sítios de escarpas erosivas em encostas sem hidromorfismo (EA e ES) a principal preocupação é o relevo e a quantidade de material esquelético do solo, com as áreas chegando a formar pavimentos desérticos induzidos pela ação antrópica ou pela condição natural local.

Para os sítios de escarpas erosivas com hidromorfismo $(\mathrm{EH})$, além do relevo e da quantidade de material esquelético, o excesso de água sazonal pode ser um fator ambiental limitante ao manejo e, ou, regeneração da vegetação local.

Para os sítios de baixada, o forte hidromorfismo é o principal fator de limitação ambiental à introdução de espécies arbóreas.

O sítio SE, por apresentar solos de relevo plano, profundos e com excesso de água não muito acentuado ao longo do ano, apresenta o maior potencial de taxa de sucesso da regeneração ambiental com espécies arbóreas entre os sítios estudados.

\section{REFERÊNCIAS}

BRASIL. Lei $n^{0}$ 4.771, de 15 de setembro de 1965. Institui o novo Código Florestal Brasileiro. Brasília, 1965. Disponível em: <http://www.jusbrasil.com.br/legislacao/ 91627/codigo-florestal-lei-4771-65>. Acesso em: 19 abr. 2012.

CURCIO, G. R. Relações entre geologia, geomorfologia, pedologia e fitossociologia nas planícies fluviais do rio Iguaçu, Paraná, Brasil. 2006. 488f. Tese (Doutorado em Engenharia Florestal) - Universidade Federal do Paraná, Curitiba, 2006.

DUARTE, M. N.; RAMOS, D. P.; LIMA, P. C. Mineralogia, química e micromorfologia de solos de uma microbacia nos Tabuleiros Costeiros do Espírito Santo. Pesquisa agropecuária brasileira, Brasília, v. 35, n. 6, p. 1237-1250, 2000.

EMPRESA BRASILEIRA DE PESQUISA AGROPECUÁRIA - EMBRAPA. Sistema brasileiro de classificação de solos. 2. ed. Brasília: Embrapa-SPI, 2006. 306p. 
MAGAlhãeS, L. T. S.; GOMES, J. B. V.; VASCO, A. N.; AGUIAR NETTO, A. O.; FERREIRA, R. A. Caracterização geo-pedológica das áreas de nascentes na bacia hidrográfica do rio Piauitinga, Sergipe, Brasil. Ambi-Agua, Taubaté, v. 7, n. 1, p. 169-181, 2012. (http://dx.doi.org/10.4136/ambi-agua.767)

FERREIRA, M. M.; FERNANDES, B.; CURI, N. Mineralogia da fração argila e estrutura de Latossolos da região Sudeste do Brasil. Revista brasileira de Ciência do Solo, Viçosa, MG, v. 23, p. 507-514, 1999.

FERREIRA, R A.; AGUIAR NETTO, A. O.; SANTOS, T. I. S.; SANTOS, B. L; MATOS, E. L. Nascentes da sub-bacia hidrográfica do rio Poxim, estado de Sergipe: da degradação à Restauração. Revista Árvore, v. 35, n. 2, p. 265-277, 2011 http://dx.doi.org/10.1590/S0100-67622011000200011

FOLEY, J. A.; DeFRIES, R.; ASNER, G. P.; BARFORD, C.; BONAN, G.; CARPENTER, S. R. et al. Global consequences of land use. Science, v. 309, p. 570-574, 2005. http://dx.doi.org/10.1126/science.1111772

GOMES, J. B. V.; BOLFE, E. L.; CURI, N.; FONTES, H. R.; BARRETO, A. C.; VIANA, R. D. Variabilidade espacial de atributos de solos em unidades de manejo em área piloto de produção integrada de coco. Revista brasileira de Ciência do Solo, v. 32, p. 24712482, 2008. http://dx.doi.org/10.1590/S0100-06832008000600024

GUERTAL, W. R.; Hall, G. F. Relating soil color to soil water table levels. The Ohio Journal of Science, v. 90, n. 4, p.118-124, 1990.

LIMA NETO, J. de A.; RIBEIRO, M. R.; CORRÊA, M. M.; SOUZA JÚNIOR, V. S .; LIMA, J. F. W. F.; FERREIRA, R. F. A. L. Caracterização e gênese do caráter coeso em latossolos amarelos e argissolos dos tabuleiros costeiros do estado de Alagoas. Revista brasileira de Ciência do Solo, Viçosa, MG, v. 33, n. 4, p. 1001-1011, 2009.

MARTINS, A. K. E.; SCHAEFER, C. E. G. R.; SILVA, E.; SOARES, V. P.; CORREA, G. R.; MENDONCA, B. A. F. Relações solo-geoambiente em áreas de ocorrência de ipucas na planície do Médio Araguaia - estado de Tocantins. Revista Árvore, Viçosa, MG, v. 30, n. 2, p. 297-310, 2006.

MOREIRA, F. D. Geotecnologia aplicada à sub-bacia hidrográfica do rio Piauitinga e suas relações ambientais. 2008. Dissertação (Mestrado em Geografia) - Núcleo de Pós-Graduação em Geografia (NPGEO), Universidade Federal de Sergipe, São Cristóvão, 2008.

MOTTA, P. E. F.; CARVALHO FILHO, A.; KER, J. C.; PEREIRA, N. R.; CARVALHO JUNIOR, W.; BLANCANEAUX, P. Relações solo-superfície geomórfica e evolução da paisagem em uma área de Planalto Central Brasileiro. Pesquisa agropecuária brasileira, Brasília, v. 37, n. 6, p. 869-878, 2002a.

MOTTA, P. E. F.; CURI, N.; OLIVEIRA FILHO, A. T.; GOMES, J. B. V. Ocorrência da macaúba em Minas Gerais: relação com atributos climáticos, pedológicos e vegetacionais. Pesquisa agropecuária brasileira, Brasília, v. 37, n. 7, p. 1023-1031, $2002 b$.

PINTO, L. V. A.; BOTELHO, S. A.; DAVIDE, A. C.; FERREIRA, E. Estudos das nascentes da bacia hidrográfica do Ribeirão Santa Cruz, Lavras, MG. Scientia Forestalis, Piracicaba, n. 65, p. 197-206, 2004.

POESEN, J.; INGELMO-SANCHEZ, F. Runoff and sediment yield from topsoils with different porosity as affected by rock fragment cover and position. Catena, v. 19, n. 5, p. 451-474, 1992. http://dx.doi.org/10.1016/0341-8162(92)90044-C 
MAGAlHÃES, L. T. S.; GOMES, J. B. V.; VASCO, A. N.; AGUIAR NETTO, A. O.; FERREIRA, R. A. Caracterização geo-pedológica das áreas de nascentes na bacia hidrográfica do rio Piauitinga, Sergipe, Brasil. Ambi-Agua, Taubaté, v. 7, n. 1, p. 169-181, 2012. (http://dx.doi.org/10.4136/ambi-agua.767)

SANTOS, R. D.; LEMOS, R. C.; SANTOS, H. G.; KER, J. C.; ANJOS, L. H. C. Manual de descrição e coleta de solos no campo. 5. ed. Viçosa, MG: SBCS, 2005. 92 p.

SERGIPE (Estado). Secretaria de Estado do Planejamento e da Ciência e Tecnologia. Superintendência de Recursos Hídricos. Sergipe: atlas digital sobre recursos hídricos. Aracajú, 2011. 